\title{
¿Descubrir, ampliar y profundizar?: una revisión de las contribuciones de la antropología a las investigaciones
del tercer sector
}

David Lewis*

\section{Resumen}

El perfil de los antropólogos y de los enfoques antropológicos en la investigación actual del tercer sector es relativamente escaso. La primera parte del artículo hace una revisión del estado del trabajo antropológico acerca de las organizaciones en general, antes de enfocarse de manera específica a los trabajos acerca del tercer sector. La segunda parte hace notar que recientemente los antropólogos han trabajado menos en esta área, pero muestra de qué manera los trabajos antropológicos recientes acerca de la burocracia, el desarrollo y las políticas públicas son altamente relevantes para los estudios del tercer sector. La conclusión del artículo es que la investigación antropológica puede descubrir más acerca del tercer sector oculto al proporcionar microrrelatos detallados, así como ampliar el espectro de los estudios del tercer sector (arrojando luz acerca de la diversidad

*London School of Economics, correo-e: D.J.Lewis@1se.ac.uk.

Economía, Sociedad y Territorio, vol. II, núm. 8, 2000, 791-815. 
de la vida organizacional y al cuestionar los prejuicios y el etnocentrismo occidentales), y, por último, puede profundizar en el análisis de los estudios del tercer sector a través del empleo distintivo de un análisis de temas sumamente complejos (como la cultura organizacional y los valores) centrado en el actor y en los procesos. Se concluye con la observación de que un mayor acercamiento a los estudios del tercer sector podría también ser benéfico para la antropología, la cual ha sido criticada en ciertos medios por su pérdida de relevancia en el mundo contemporáneo.

Palabras clave: organizaciones no gubernamentales, antropología, asociaciones voluntarias, asociaciones no lucrativas.

\section{Abstract}

The profile of anthropologists and anthropological approaches in current third sector research is relatively low. The first part of the paper reviews the status of anthropological work dealing organizations generally before focusing more specifically on work on the third sector. This paper notes that anthropologists have more recently done less work in this area, but shows how more recent anthropological work on bureaucracy, development and policy issues is highly relevant to third sector research and the second part of the paper briefly reviews such work. The paper concludes that anthropological research can firstly reveal more of the hidden third sector by providing detailed micro-accounts; secondly it can widen the scope of third sector research (by throwing light on the diversity of organizational life and challenging Western bias and ethnocentricity), and thirdly deepen the analysis of third sector research through its distinctive use of an actor-centered, process-based analysis of highly complex issues (such as organizational culture, values). The paper concludes with the observation that closer engagement with third sector research might also benefit current anthropology, which has been criticized in some quarters as losing relevance to the contemporary world.

Keywords: nongovernmental organizations, anthropology, voluntary associations, nonprofit organizations. 


\section{Introducción $^{1}$}

En años recientes, el término tercer sector ha ganado popularidad entre los investigadores y los autores de las políticas públicas para referirse al laxo grupo de organizaciones que, en diferentes culturas y contextos, son denominadas como voluntarias, no gubernamentales, o no lucrativas. El perfil de tales organizaciones del tercer sector alrededor del mundo se ha incrementado dramáticamente durante las últimas dos décadas, fenómeno que es definido por Salamon (1994) como una "revolución global de las asociaciones". Tanto los países industrializados como aquellos que reciben ayuda han sido testigos de sus actividades, desde la elaboración de políticas públicas hasta la investigación. Las asociaciones de investigación académica profesional, como la Asociación para la Investigación de las Agencias no Lucrativas y Voluntarias (ARNOVA, por sus siglas en inglés), y más recientemente la Sociedad Internacional para la Investigación del Tercer Sector (ISTR, siglas en inglés), agrupan entre sus miembros a cientos de investigadores de diversas disciplinas, y ambas llevan a cabo conferencias académicas internacionales de manera periódica.

El tercer sector, llamado así por su distinción en términos generales, de los otros dos sectores -el gobierno y la empresa-, ha sido reconocido como un actor importante en la movilización comunitaria y el apoyo autogestionado en las obras de beneficencia, la dotación de servicios y las actividades de campaña (Salamon y Anheier, 1997). El tercer sector agrupa una amplia variedad de organizaciones, desde grandes ONG (organizaciones no gubernamentales) y sindicatos, hasta grupos informales de apoyo autogestionado y organizaciones comunitarias. Las actividades llevadas a cabo por tales organizaciones tienen lugar en una amplia gama de contextos, incluyendo el laboral, la esfera política, el ámbito del activismo religioso, o el mundo de las agencias e instituciones internacionales de desarrollo. El nuevo interés en los conceptos de sociedad civil (Hann y Dunn, 1996) y capital social (Putnam, 1994) sólo ha servido para atraer más la atención sobre el tercer sector en tanto metáfora que ayude a entender esta "familia" de organizaciones.

${ }^{1}$ Una primera versión de este documento fue presentada en la conferencia de la Association for Research on Nonprofit and Voluntary Agencies (ARNOVA) en Seattle, en noviembre de 1998 y fue publicada en Human Organization, vol. 8, núm. 1, enero de 1999, con el título: "Revealing, widening, deepening?: a review of the existing and potential contribution of anthropological approaches to 'third sector' research". Traducción del inglés de Alma Mancilla Sánchez. 
Durante la última década aproximadamente, una agrupación interdisciplinaria de académicos, principalmente europeos y norteamericanos, ha comenzado a enfocarse en la problemática del tercer sector, concentrándola en un campo que puede ser denominado estudios del tercer sector (por ejemplo, Powell, 1987; Salamon y Anheier, 1997; Billis y Harris, 1996). Estas investigaciones han examinado temáticas como el origen de las organizaciones del tercer sector, la gama de organizaciones existentes, sus relaciones con las políticas públicas y los retos organizacionales que estas organizaciones enfrentan. Esta literatura especializada se ha complementado con un crecimiento paralelo del interés académico en las ONG como agentes del desarrollo por parte de los investigadores de los estudios del desarrollo (por ejemplo, Edwards y Hulme, 1992; Farrington y Bebbington, 1993; Hulme y Edwards, 1997). Este segundo tipo de literatura ha examinado el papel que han jugado las organizaciones de los países industrializados y de aquellos "del sur" en las tareas del "desarrollo" -desde la instrumentación de proyectos hasta la organización de campañas en torno a problemas ambientales o de derechos humanos. Sin embargo, a pesar de abarcar terrenos que se superponen, estas dos literaturas se han mantenido en gran medida separadas (Lewis, 1998).

Este trabajo postula que ninguno de los dos grupos de investigadores ha hecho todavía un uso efectivo de los enfoques antropológicos para la comprensión de las organizaciones del tercer sector. Los economistas, los sociólogos y los politólogos han realizado contribuciones significativas al desarrollo de los estudios del tercer sector. Por ejemplo, el economista Burton Weisbrod (1977) intentó explicar la existencia del sector no lucrativo mostrando cómo los mercados abandonan a algunos consumidores. El sociólogo Etzioni proporcionó un marco interpretativo que postula un "acuerdo" entre los tres principales tipos de organizaciones, lo que aclara el carácter específico de la cohesión organizacional del tercer sector (Etzioni, 1961). El trabajo de Fisher acerca de las ONG y los sistemas políticos en los países en vías de desarrollo proporciona un enfoque desde la ciencia política para el estudio de estas organizaciones como actores políticos. Sin embargo, hasta ahora se ha hecho relativamente poco uso del trabajo antropológico; ni tampoco ha habido una tendencia por parte de los antropólogos a involucrarse de manera formal con los estudios del tercer sector. Los estudios del tercer sector se han acercado ocasionalmente a los antropólogos socia- 
les o culturales. Por ejemplo, Anheier (1987) hace referencia al trabajo etnográfico de los antropólogos acerca de las organizaciones voluntarias en África, mientras Billis (1993) se acerca ligeramente a las ideas del antropólogo británico Edmund Leach en su trabajo sobre la transición y la ambigüedad al interior de las agencias burocráticas voluntarias.

Como es señalado por Haviland (1974), el concepto de organización ha sido, desde sus inicios, un concepto prominente en los estudios antropológicos, la mayoría de los cuales pretendían entender la manera en que las diferentes sociedades se organizaban en términos de parentesco, política y economía, y religión. Más recientemente, las propias organizaciones han llegado a ser concebidas como tipos de "comunidades" por parte de algunos antropólogos que han estudiado agrupaciones de todas clases, desde grupos de edad en África hasta empresas comerciales en los Estados Unidos (Chambers, 1985).

Existe un enorme potencial en el trabajo antropológico para enriquecer los estudios del tercer sector, tanto en términos de compartir información etnográfica ya existente con los estudiosos del tercer sector, como en los enfoques teóricos y metodológicos que la antropología ofrece para futuras investigaciones. Existe también una oportunidad para que un mayor número de antropólogos hagan contribuciones importantes al desarrollo de este campo de estudio.

\section{Contribuciones existentes y potenciales}

La antropología ha sido asociada con el estudio de las comunidades "tradicionales" no occidentales, especialmente de aquellas que se encontraban subordinadas, marginadas o geográficamente remotas. Existe sin lugar a dudas una gran riqueza de material etnográfico acerca de las organizaciones no gubernamentales y voluntarias no occidentales dentro de muchas de las monografías antropológicas realizadas desde que la disciplina ha existido. Sin embargo, existe consenso respecto a que la tan estrecha visión de los antropólogos como viajeros y proveedores de lo exótico pasó de moda hace mucho, al menos para aquellos dentro de la disciplina antropológica. Desde la década de 1950 los antropólogos comenzaron a enfocarse en los estudios organizacionales en las sociedades industrializadas, y en la idea de estudiar las organizaciones como comunidades. La investigación antropológica de años más recientes se ha interesado no sólo en las comunidades "en 
casa", sino en las relaciones entre las comunidades y la instrumentación más amplia de políticas de educación, salud y burocracia, o entre éstas y las instituciones internacionales de desarrollo (Wright, 1994). Más recientemente, la necesidad de que los antropólogos estudien y se enfoquen en los poderosos y en quienes integran las corrientes principales (Gardner y Lewis, 1996) ha sido una preocupación generalizada.

Los antropólogos han aportado una metodología distintiva a todas estas áreas de la investigación: un enfoque que anhela entender las comunidades en pequeña escala fundamentalmente a través de largas estancias de trabajo de campo que faciliten la recolección cara a cara de la información, a menudo mediante el empleo de una metodología de investigación cualitativa de observación participante. Este enfoque interpretativo de pequeña escala ha sido lo que ha distinguido al trabajo de los antropólogos del de los sociólogos. Algo que resulta de particular interés para los estudios del tercer sector es la práctica de la etnografía organizacional en donde las organizaciones y sus relaciones son tratados como unidades de análisis empleando la observación participante. Sin embargo, este tipo de trabajo se ha vuelto menos común, y la relación entre los antropólogos y los teóricos de las organizaciones ha declinado en años recientes (Bate, 1997). Como argumenta Bate, la investigación etnográfica se encuentra en el corazón de la antropología y proporciona una metodología, una forma de pensar y una forma de escribir que puede enriquecer mucho a la escritura actual acerca de las organizaciones, la cual a menudo se ve debilitada por su reificación de la cultura en las organizaciones y por su pensamiento conceptual de "rápida fijación”. La panorámica y la crítica a la etnografía institucional proporcionada por Bate podría, como aquí se sugiere, ampliarse de manera efectiva a las organizaciones del tercer sector.

Pero la antropología ofrece mucho más que sólo una metodología particular, la cual, después de todo, ya no es única de la disciplina y ahora es ampliamente utilizada entre otros científicos sociales. Como ha demostrado de manera convincente Gledhill (1994), la contribución distintiva de la antropología a las ciencias sociales es principalmente aquella de orden teórico que:

...pretende examinar las realidades sociales dentro de un marco de referencia intercultural. Al esforzarse por trascender una visión del mundo basada únicamente en las premisas de la cultura y la historia europeas, los antropólogos son también impulsados a mirar más allá del mundo de las apariencias y los presupuestos de la vida social en gene- 
ral. Esto debería ayudarnos a buscar análisis críticos de las ideologías y las relaciones de poder en todas las sociedades, incluidas las occidentales (Gledhill, 1994: 7-8).

El estudio de las organizaciones del tercer sector en Occidente, ya sean las organizaciones norteamericanas sin fines de lucro, las agencias voluntarias británicas o las ONG internacionales para el desarrollo, trae consigo una serie de supuestos y prejuicios arraigados en la historia, los valores y la cultura de Occidente. Es sólo actualmente que éstos comienzan a ser cuestionados a medida que los estudios comienzan a ampliarse y a internacionalizar sus objetivos (por ejemplo Salamon y Anheier, 1997).

En las secciones restantes se discuten tres tipos generales de contribuciones antropológicas potenciales a la investigación del tercer sector: descubrir (poniendo de manifiesto áreas del tercer sector que actualmente reciben poca atención); ampliar (abriendo importantes perspectivas no occidentales acerca de las organizaciones del tercer sector) y profundizar (en una perspectiva crítica particular acerca de las organizaciones del tercer sector y sus contextos). Este trabajo no pretende presentar una revisión exhaustiva de la literatura especializada, sino que emplea trabajos de antropólogos seleccionados para ilustrar estos tres puntos y para sugerir el potencial para enriquecer los estudios del tercer sector.

\section{Descubrir más en torno al tercer sector}

El tercer sector contiene un grupo diverso de organizaciones. Mucha de la literatura especializada en el estudio del tercer sector se ha concentrado hasta ahora en las formas de organización más grandes y burocráticas, tales como las ONG internacionales, como Oxfain o la Fundación Save the Children, o las agencias de servicios de beneficencia, como la YMCA. Se ha enfatizado mucho menos en la pequeña escala, en las formas locales o "asociacionales" de actividad, particularmente en aquellas que tienen que ver con el "apoyo autogestionado" y la ayuda mutua en organizaciones de socios. Se ha observado un prejuicio en las investigaciones del tercer sector tanto en los Estados Unidos como en Gran Bretaña (Horton Smith, 1997; Rochester, 1998). Puede notarse también un prejuicio similar en la literatura sobre ONG (Edwards y Hulme, 1995). La existencia de investigación etnográfica tanto de sociedades occidentales como de no occidentales podría pro- 
porcionar los fundamentos sobre los cuales comenzar a emprender el balance. Los microrrelatos ricamente detallados que la antropología puede proporcionar resultan muy apropiados para la exploración de partes menos "visibles" del sector.

Muchos de los primeros trabajos en torno a las asociaciones voluntarias llevados a cabo por antropólogos se realizó en un contexto de acelerado cambio social. En las décadas de 1950 y 1960 los antropólogos que trabajaban en África se interesaron en el papel de las asociaciones voluntarias que ellos veían como capaces de proporcionar mecanismos adaptativos para los miembros de las comunidades que experimentaban cambios acelerados, como la urbanización (Banton, 1968). Los miembros de las comunidades sometidas a profundos cambios económicos y sociales se encontraban estructurados con anterioridad a través de relaciones de parentesco en zonas predominantemente rurales, pero fueron reorganizados en nuevos contextos urbanos capitalistas (Haviland, 1974). Kerri (1976: 23) llama a estas asociaciones voluntarias o de interés común, y sugiere que han sido estudiadas como "mecanismos adaptativos en situaciones de cambio social, cultural, ecológico y tecnológico". Sintetizando estos primeros trabajos, Kerri prosigue planteando que bajo ciertas condiciones de cambio, la base organizativa de ciertos grupos se reestructura alrededor de intereses comunes, como la ocupación, la profesión, la recreación o la espiritualidad, lo que proporciona un medio para que los grupos sociales se adapten o reconfiguren a los nuevos contextos urbanos. La razón de esto es el hecho de que las organizaciones voluntarias, que se fundan en el interés común y en la participación voluntaria de sus miembros, carecen de la rigidez de los grupos basados en el parentesco (que son la base de la propiedad de la tierra y del intercambio social) o de las unidades territoriales (por ejemplo las estructuras de gobierno a niveles local o nacional).

Little (1965) por ejemplo, quien comenzó escribiendo en África Occidental a finales de la década de 1940, describió cómo las instituciones tribales de los migrantes urbanos se desintegran y son reemplazadas o suplantadas por nuevos grupos. Estas nuevas asociaciones cubren las necesidades de la gente en materia económica, religiosa o de otra índole y ayudan a la adaptación al nuevo entorno en términos de compañía, protección y comportamiento adecuado. Muchas formas tradicionales de organización persisten, pero la familia tiende a perder su anterior significación como proveedora de ayuda y apoyo mutuos, y son los 
grupos de edad y las sociedades secretas las que asumen este papel. Little clasifica las asociaciones en cuatro tipos: uniones tribales, asociaciones de amistad, asociaciones ocupacionales y asociaciones recreativas, y las concibe como proveedoras de un "puente" cultural que lleva a los individuos del contexto "tradicional" al "moderno". Banton (1968) plantea que la autoridad transmitida en algunas sociedades tribales incrementa la posibilidad de que se formen asociaciones contractuales, de interés común, en los contextos urbanos, ya sea porque los hombres jóvenes rechazan la autoridad tradicional, o porque obtienen un conocimiento acerca de medios alternativos más apropiados para lidiar con los problemas urbanos. A medida que el "estatus adscrito" se vuelve menos importante, estas asociaciones permiten al nuevo migrante ajustarse a su estatus "adquirido". Aunque hace mucho que tal dualismo durkheimiano ha sido superado por el pensamiento antropológico de carácter estructuralista o posmoderno, tales posturas siguen siendo importantes por la riqueza de sus detalles etnográficos.

Otro punto de partida de los primeros trabajos etnográficos para los investigadores del tercer sector es la gran cantidad de trabajos antropológicos acerca de las asociaciones rotativas de crédito, una variedad de grupo de asistencia personal común en muchos países. Ha habido una larga discusión en la literatura antropológica acerca de este tipo de asociación. Uno de los textos preliminares fue el de Geertz (1962: 243), quien escribió con base en su trabajo de campo en Indonesia:

...el principio básico en el que se funda la asociación rotativa de crédito es la misma en todas partes: un fondo global, conformado por contribuciones fijas de cada uno de los miembros de la asociación, es distribuido, a intervalos fijos y en su totalidad, a cada miembro de la asociación a la vez.

Geertz localizó este tipo de organización en las sociedades en transición de un orientación tradicional agraria a una comercial moderna. Un trabajo más reciente de Chhetri (1995) prosigue con la temática y examina la asociación nepalí de crédito dhikuri como un mecanismo adaptativo arraigado en la comunidad extensa, a través de la cual la gente también cuestiona la legitimidad de las instituciones bancarias modernas, puesto que se funda en la confianza personal más que en las relaciones impersonales. 
El análisis de problemáticas de género en relación con el tercer sector también puede expandirse mediante las perspectivas antropológicas. Muchos grupos autoconstituidos son iniciados por mujeres - por ejemplo los grupos harambee en Kenya- y en muchas ocasiones ejercen múltiples funciones de apoyo mutuo, iniciativa económica y reducción de la dependencia con respecto a los parientes varones (Moore, 1988). El trabajo antropológico previo, aunque poco sofisticado en términos teóricos, proporciona ricos detalles etnográficos acerca de las variedades de organizaciones de mujeres, particularmente en el contexto africano. Little (1972) describe el papel de las asociaciones voluntarias como vehículos de movilidad social para las mujeres de África Occidental, quienes transitan de los roles "tradicionales" al estatus "adquirido". Estas organizaciones proporcionan esquemas de beneficio mutuo, contactos comerciales y capital, así como ayuda para sobrellevar la soledad en los nuevos entornos urbanos. A medida que las mujeres se alejaban del estatus tradicionalmente adscrito, la movilidad fue posible mediante la identificación con la posición del esposo, la membresía en una asociación voluntaria, y el comercio y el prestigio obtenidos por las vías de la educación o del matrimonio de los hijos. A pesar del vínculo entre muchos de los trabajos antropológicos de este periodo con las simplistas teorías de la modernización del desarrollo, comunes en este momento, el registro etnográfico de tales organizaciones aún nos puede revelar un poco más acerca de ese más amplio tercer sector.

La investigación antropológica de este tipo no se ha visto confinada al contexto africano, sino que ha examinado influencias más extensas en la emergencia de asociaciones voluntarias también en los países industrializados. Después de realizar trabajos en Japón, en los cuales muestra la manera en que las asociaciones de interés común han crecido en importancia paralela a las instituciones de beneficencia y han asumido muchas de las funciones del parentesco, Norbeck (1972) discute que tales asociaciones de interés común deberían ser vistas como una categoría general de la cual las asociaciones voluntarias conforman una subcategoría, puesto que en algunas ocasiones la membresía a estas asociaciones es incitada por el gobierno. Estas asociaciones, argumenta el autor, son tanto indicadores como instrumentos de cambio, lo mismo en zonas urbanas que rurales. El trabajo en Europa y en Norteamérica ha reflejado un interés similar por parte de los antropólogos. Anderson y Anderson (1959) han es- 
tudiado comunidades en Dinamarca y Francia, y sugieren que las asociaciones voluntarias responden a necesidades que, o bien están fuera de las preocupaciones del gobierno, o no son aún lo suficientemente importantes como para recibir atención. Por ejemplo, las necesidades de los migrantes recién llegados o de las minorías étnicas podrían entrar dentro de esta categoría. Se ha encontrado que entre las comunidades ucranianas en Francia las asociaciones unifican a los migrantes en las zonas urbanas más que las asociaciones en sus comunidades de origen, estructuradas principalmente en torno al parentesco y al territorio.

Los antropólogos también han comenzado a establecer vínculos entre modos de producción cambiantes, políticas estatales, y respuestas y estrategias de supervivencia locales. El trabajo de Hamer (1967) entre los sidamo del suroeste de Etiopía vincula el incremento de las asociaciones voluntarias con el crecimiento de una economía monetaria agrícola y un Estado centralizado. Las asociaciones laborales se han formado para facilitar la cosecha de café, en parte ayudadas por las iglesias misioneras, porque la familia extensa tradicional ha resultado insuficiente para tal fin. El conocimiento de otras organizaciones formales sancionadas por el Estado en otros lugares de Etiopía también ha facilitado este incremento. Moore (1988) también señala que las iniciativas de asistencia personal -como las harambee en Kenya- normalmente son resultado de una combinación de factores tanto internos como externos.

\section{Ampliar el espectro de las investigaciones del tercer sector}

La literatura existente, salvo notables excepciones, tiende a arraigarse en investigaciones llevadas a cabo principalmente en el tercer sector nacional de Gran Bretaña y los Estados Unidos, en donde existen historias distintivas locales acerca de las organizaciones "caritativas" y "no lucrativas". Mucha menos atención han merecido las múltiples formas de actividad organizacional que existen fuera de las culturas dominantes de estas sociedades (por ejemplo el tipo de organizaciones del tercer sector formadas por minorías, refugiados y migrantes económicos), o la variedad de acciones voluntarias en el resto del mundo (como los grupos de crédito rotativo en las sociedades campesinas, o las ideologías locales de asistencia autogestionada).

Este prejuicio deja abierta al cuestionamiento a una gran cantidad de definiciones, términos y suposiciones. ¿Es el tercer 
sector un concepto que sólo tiene significado en ciertas sociedades? Los valores culturales que crean y sostienen a estas organizaciones pueden requerir ser comprendidos dentro de sus propios términos. ¿Cómo se manifiesta el concepto de "voluntariedad" en otras culturas? ¿Qué es lo que se ve reflejado en el hecho de etiquetar a ciertas organizaciones como "voluntarias" o "no gubernamentales" en algunos contextos, y no en otros? (Lewis, 1998). La variedad de formas organizacionales y de enfoques de negociación también debe ser considerada. ¿Pueden las formas indígenas de negociación contrastarse con aquellas cuya base es el discurso y el conocimiento occidental?

Un área importante sobre la cual el trabajo antropológico existente arroja luz es el análisis del encuentro histórico entre formas de organización occidentales y no occidentales. Por ejemplo, Meillassoux (1968) estudia las organizaciones voluntarias en Bamako y concluye que las organizaciones tradicionales de las aldeas, encargadas de la organización del trabajo y la diversión, y que emergen durante el periodo colonial, fueron eliminadas por el gobierno poscolonial, que pretendió crear sus propias estructuras a través del partido político nacional. Sin embargo, algunas de estas viejas asociaciones persistieron. Ottenberg (1955) describe las asociaciones de mejoramiento entre los Afikpo Ibo del sur de Nigeria, en donde los hombres jóvenes, a menudo empleados del gobierno, trabajan para el mejoramiento de la aldea a través de actividades como eventos sociales, escuelas, hospitales, caminos y becas. Este autor sugiere que las rivalidades que existían en el pasado en la aldea, y que a menudo implicaban una guerra, han evolucionado hasta convertirse en modernas rivalidades interaldeanas basadas en la dotación de educación y el mantenimiento de la infraestructura. De manera que estas asociaciones combinan elementos tanto "tradicionales" como "modernos". En Asia, un estudio de Anderson (1964) acerca de las asociaciones voluntarias en Hyderabad, en la India, reveló que un modelo occidental "importado" (o impuesto) de organizaciones voluntarias formales coexistía con las estructuras informales indígenas. Esto ha llevado a que estas nuevas organizaciones se caractericen por liderazgos poco confiables o corruptos y por una "ambigüedad de roles". Anderson sugiere que en su proceso de planeación el Estado indio ha puesto sus esperanzas en tales organizaciones basándose en experiencias tomadas de los roles de éstas en las sociedades occidentales. 
Una segunda área clave para ampliar el alcance de los estudios del tercer sector es la comprensión de las diferentes perspectivas culturales en conceptos como "voluntariedad" y "donación”. Existe un vínculo importante para entender la donación caritativa, la asistencia para el desarrollo y la filantropía, que puede provenir de la tradición antropológica que pretende entender los dones y la reciprocidad, y cuyos orígenes se encuentran en el trabajo de Mauss (1954). Como argumenta Mauss, el otorgamiento de un don confiere poder al que lo otorga. Un estudio reciente de una aldea en donde se han examinado estas ideas en el contexto de los trabajos para el desarrollo, es el de Vandergeest (1991), quien demuestra de manera convincente cómo el Estado y otras agencias para el desarrollo, en su intento por modernizar las zonas rurales, se han apropiado del lenguaje del don en Tailandia desde la década de 1930, en contradicción con las más igualitarias tradiciones locales de ayuda mutua. El lenguaje de la ayuda ha sido cooptado y transformado por los desarrollistas para obligar a los aldeanos a participar en proyectos de desarrollo. Los trabajos de Vandergeest pretenden demostrar que la visión de comunidad en la aldea precapitalista bien podría ser un construcción del presente. En la década de 1930, existían proyectos de desarrollo (que ahora son "recordados" como formas de ayuda mutua entre las aldeas) que eran en realidad formas de conformación del Estado que provenían del exterior (y que eran expresadas en términos de dones provenientes del Estado que vinculaban a "líderes" y "seguidores" en busca del "bienestar común”), y que en lugar de ayudar a los aldeanos a ayudarse a sí mismos, enfatizaban en el "reemplazo del lenguaje de la ayuda por el lenguaje de los 'derechos' (Ibid., p.426). Los aldeanos en ese momento "debían ayudar" por ejemplo, como trabajadores en los campos de las élites locales.

Sin embargo sí existen formas de "ayuda" mutua en las aldeas; por ejemplo las redes informales mediante las cuales las mujeres trasplantan y cosechan el arroz, creando así grupos "políticos" que también proporcionan ayuda contra los problemas con esposos o padres:

...las relaciones de ayuda o de "intercambio de dones" no están asociadas únicamente con el poder servil, desigual; o con el control y la regulación. También pueden usarse para crear redes de ayuda mutua (Vandergeest, 1991: 4-38). 
El autor continúa discutiendo que los dones confieren poder a aquellos que los otorgan, quienes pueden retirarlos cuando decidan, además pueden imponer condiciones a aquellos que los reciben. Esto puede contrastarse con los derechos, que otorgan poder a quien los recibe al trasladar la obligación a quien los otorga, como cuando el Estado está obligado a garantizar la seguridad, o la participación democrática. Otro trabajo de Stirrat y Henkel (1997) desarrolla las ideas de Mauss en el contexto de las primeras relaciones entre las organizaciones no gubernamentales occidentales y sus contrapartes del sur.

El trabajo de los antropólogos no sólo resulta de valor en el extremo de las asociaciones en pequeña escala del tercer sector, sino también dentro de las burocracias. Como Billis (1993) y otros autores han demostrado, el estudio de la burocracia es central para la comprensión de los retos organizacionales enfrentados por organizaciones de mayor escala en el tercer sector. La burocracia también ha sido durante mucho tiempo de interés para los antropólogos, Heyman (1995) ha revisado recientemente varios enfoques. Heyman argumenta que el trabajo original de Weber acerca de las burocracias llevó a los sociólogos y a otros investigadores a restringir sus intereses de investigación al diagnóstico de problemas administrativos con un énfasis excesivo en los aspectos internos de las burocracias. El autor enfatiza que Weber se interesaba también en la "modernización del poder societal" implicada en el viraje del gobierno de las élites a las instituciones del capitalismo y la democracia. Este segundo aspecto de su trabajo ha tenido continuidad por parte de, entre otros, los antropólogos.

Herzfeld (1992) señala que la burocracia occidental "moderna" no puede simplemente ser contrastada con formas "primitivas" o no occidentales de organización, sino que puede ser analizada de formas similares a las empleadas por los antropólogos en el estudio de los patrones formales del ritual que son prescritos al interior de cualquier sociedad. Mientras que la noción de jerarquía no es únicamente un concepto occidental, puede percibirse a las nociones weberianas de la burocracia como representativas de una forma de pensamiento distintiva de la tradición renacentista y moderna, con una distinción simbólica entre quienes están dentro y ocupan una posición privilegiada, y quienes están fuera, distinción que no necesariamente existe en todas las sociedades (Herzfeld, 1992); es la idea de superioridad la que resulta occidental y culturalmente distintiva. El concepto de res- 
ponsabilidad, aunque universal, es "una amalgama de ideas socialmente producidas acerca de la persona, la presencia y la forma de gobierno" con "significados culturalmente específicos" (Ibid., p.47). Herzfeld muestra cómo en el contexto de Grecia, por ejemplo, la forma simbólica de la burocracia es una cubierta para las tácticas de "toma del poder, humillación e indiferencia".

\section{Profundizar el análisis: nuevas perspectivas críticas}

La antropología, más que ser simplemente una metodología de investigación y una forma de develar la diversidad de la vida social, puede también proporcionar un enfoque crítico particular a nuestra comprensión de las organizaciones y sus contextos. Esta sección explora una muestra de investigaciones que resultan relevantes para los estudios del tercer sector, considerando dos temas principales: la organización y las políticas.

La primera temática hace referencia a los retos en la comprensión de cómo operan las organizaciones. Durante muchos años han existido vínculos entre la antropología y los estudios organizacionales. En la década de 1920, los antropólogos contribuyeron a las teorías científicas de la dirección de Taylor con estudios de dos plantas de la Western Electric Hawthorne en Illinois. Estos trabajos enfatizaban el papel de los dirigentes formales por encima de otras perspectivas más participativas, apoyadas en los trabajos realizados por Gluckman y la Escuela de Manchester en las décadas de 1950 y 1960, perspectivas que enfatizaban en el contexto más amplio de la situación laboral y en las maneras en que la gente construye significados acerca de la fábrica partiendo de un repertorio cultural más amplio de roles sociales. Pero a finales de 1960 los antropólogos abandonaron el estudio de las organizaciones occidentales para desplazarse al estudio de las organizaciones del tercer mundo, mientras que los estudios organizacionales adoptaban el paradigma positivista y se alejaban de los enfoques interpretativos (Wright, 1994).

Los conceptos antropológicos han comenzado a influir en los intentos de los teóricos organizacionales por entender el elusivo concepto de cultura al interior de las organizaciones (Wright, 1994). Atañe a la antropología el estudio del análisis y la interpretación cultural, ya sea en el estudio del parentesco en pequeñas sociedades aisladas, o en las formas en que una gran empresa emplea a las personas (Chambers, 1985). En este sentido, la cultura se refiere a la información y a la interpretación de 
esta información por parte de la gente, así como a los procesos a través de los cuales estos significados son transmitidos entre las personas. Los debates en torno a la cultura han propiciado de nueva cuenta un diálogo entre los antropólogos y los teóricos organizacionales. El énfasis de Geertz (1973) en la cultura como proceso es complementado por un énfasis en el lenguaje y el poder, para demostrar cómo los discursos son construidos y debatidos tanto al interior de las organizaciones como en relación a sus contextos más amplios. Wright concluye que:

La cultura tiene una doble faceta. La cultura es un concepto analítico para problematizar el campo de las organizaciones; en ese campo, la cultura es una reivindicación ideológica, arraigada en condiciones históricas y sujeta a desafíos.

No quiere decir que los antropólogos y los teóricos organizacionales necesariamente vean a la cultura en los mismos términos. El concepto de cultura prevalece cada vez más en los estudios organizacionales, y mientras que sus orígenes se atribuyen al trabajo de los antropólogos, las dos disciplinas emplean el término de maneras diferentes. En los estudios organizacionales el interés en la cultura se ha dado en el contexto de: i) El manejo en diferentes contextos culturales nacionales, ii) la integración de los trabajadores con diferentes identidades étnicas en una sola unidad, iii) las actitudes de la fuerza de trabajo y iv) la cultura colectiva fomentada por los dirigentes para sus empresas (Wright, 1994). Las ideas antropológicas acerca de la cultura también han sido llevadas al campo de los estudios organizacionales, a medida que la visión de las organizaciones como estructuras racionales ha sido puesta en tela de juicio por una perspectiva posmoderna de las organizaciones como "lugares de construcción de significados”. Pero de acuerdo a Wright (1994: 3) lo que prevalece es una desarticulación en donde los teóricos organizacionales tienden a ver la cultura como algo que la organización tiene y que puede ser manipulada, más que como algo que la organización es. Las ideas antropológicas acerca de la cultura como una entidad relacionada con el conflicto, la negociación y el proceso, algunas veces se han solidificado como herramienta ideológica del control directivo:

...para un antropólogo influenciado por las ideas de Geertz, es más probable que "participación" implique un repertorio de ideas que son continuamente reelaboradas mediante formas creativas que son sistemáticas y explicables, pero no predecibles. No solamente es esencial la 
ambigüedad, sino que provee el espacio para esta reelaboración; pero se trata de un proceso político: los significados de los conceptos y símbolos no solamente no están fijados, sino que son constantemente debatidos (Wright, 1994: 4).

Pasando al asunto de las políticas, los antropólogos han tendido a investigar cómo éstas se generan y se implementan (van Willingen, 1993). Los discernimientos antropológicos pueden llevar a la discusión acerca de las políticas y al reconocimiento de cómo ciertos grupos de personas (particularmente aquellos que se encuentran fuera de los grupos socialmente dominantes) responden a circunstancias sobre las cuales tienen poco control, por ejemplo aquellos grupos de personas afectadas por el estado modernizador (Chambers, 1985: 188):

Si el principal objetivo de la antropología durante el siglo pasado fue mejorar nuestra comprensión del proceso cultural con base en la investigación intercultural, el nuevo objetivo principal de los antropólogos aplicados es la comprensión de cómo los procesos culturales afectan las circunstancias de la toma de decisiones en las políticas públicas. Es difícil imaginar cómo puede esto llevarse a cabo sin prestar a aquellos que crean, transmiten e implementan las políticas, la misma atención que prestamos a aquellos que se ven más afectados por ellas.

Para las ONG comprometidas con el desarrollo, los antropólogos pueden también subrayar aspectos de las políticas de desarrollo. Los antropólogos han aportado nuevas perspectivas al contexto de las políticas en el que operan las organizaciones, en particular la crítica antropológica a la industria del desarrollo y a sus instituciones (Ferguson, 1990; Escobar, 1995; Gardner y Lewis, 1996).

Una de las áreas clave en la cual los antropólogos han trabajado es la forma en que las políticas son llevadas a la práctica. Esto ha implicado a menudo el observar situaciones que involucran el trabajo de organizaciones del tercer sector. Por ejemplo, Kurtz (1973) ha analizado los problemas de la iniciativa "guerra contra la pobreza” en California, durante la década de 1960. El autor demuestra que los líderes de un Consejo Local de Acción Comunitaria, de corte popular, fueron contratados para dirigir un programa contra la pobreza, pero fueron burocratizados por el grupo dominante y sus acciones comenzaron a reflejar los intereses de su nuevo estatus de clase media más que los intereses de las comunidades que éstos representaban. Pero existe también otra idea que ha recibido menos atención por parte de todos: la 
forma en que los programas de cambio son formulados y administrados tanto en la esfera informal como en la formal. Salisbury (1977) por ejemplo, desarrolló un enfoque que desconstruye diferentes realidades de diferentes "actores" al interior de un proyecto de desarrollo, en lo que, para identificar diferentes significados y comprensiones, ella llama prisma de percepciones. Estos enfoques son de gran relevancia para las ONG que participan a menudo en programas de desarrollo.

Volviendo a nuestra discusión previa acerca de la burocracia, los antropólogos han examinado las formas en que se relacionan las políticas con su instrumentación. Heyman sugiere que la antropología de la burocracia tiene un papel útil que cumplir para poder ir más allá de las políticas y los objetivos oficiales formalmente enunciados, y comprender el despliegue del poder organizado. En particular, se enfoca en las relaciones entre los trabajadores de la burocracia y las personas con las que éstos trabajan o sobre las que ejercen poder. Las investigaciones de Heyman se refieren al servicio de inmigración de los Estados Unidos en la frontera mexicana, uno de los mayores intentos en el mundo por controlar a la gente pero que, a pesar de arrestar a más de un millón de personas al año, fracasa enormemente en su labor primaria de evitar el ingreso ilegal a los Estados Unidos. No sería difícil discutir el caso de que el propósito enunciado de la industria contra la pobreza ha sido similarmente ineficaz. El trabajo de Heyman (1995: 263) se enfoca en lo que él llama trabajo del pensamiento, un concepto que el autor crea y usa para analizar la lucha inevitable entre las burocracias:

...Los trabajadores burocráticos deben pensar por ellos mismos debido a la naturaleza de sus tareas, sin embargo estos trabajadores deben ser controlados en tanto pensadores para asegurar la producción regular de los deberes de control.

En otras palabras, las burocracias generan relaciones sociales, y éstas sólo pueden ser entendidas si nos desplazamos más allá de la simple mirada a la estructura interna para incluir las relaciones externas entre controladores y controlados, lo que ayuda a determinar las culturas y los procesos organizacionales. La forma en que ciertos tipos de ONG trabajan con las comunidades, y las formas en que se reproducen los valores y la filosofía del desarrollo de las organizaciones al interior de las ONG pueden ser provechosamente analizadas empleando este tipo de perspectiva acerca de la burocracia. 
Finalmente, el problema de la construcción de las políticas en relación con las organizaciones no lucrativas no ha sido suficientemente investigado. Hay evidencia potencialmente útil proveniente de los trabajos antropológicos que sugiere que la racionalidad de la mayor parte de las organizaciones es compleja y ambigua (Quarles van Ufford, 1993). Más que simplemente cumplir las políticas, estas organizaciones generan intereses y objetivos propios, que son tanto determinados como determinantes de las políticas ambientales. Estas ideas han sido desarrolladas de manera detallada por antropólogos como Ferguson (1990) y Escobar (1995) para demostrar de qué manera los "discursos" de las políticas están vinculados con sus resultados en formas que sirven a intereses y estructuras de poder menos explícitas.

\section{Conclusiones}

Resulta sorprendente que el trabajo antropológico hasta ahora no haya contribuido de manera significativa a la creciente área de investigación de las organizaciones no lucrativas. Hay pocos antropólogos entre los miembros de ARNOVA o ISSTR y los artículos de investigación escritos desde una perspectiva antropológica rara vez aparecen en las revistas académicas acerca del tercer sector. Mucho del material etnográfico a que se hace referencia en este trabajo no es nuevo, pero muy poco de él se ha abierto camino en el mundo de los especialistas del tercer sector. Sin embargo, el extenso corpus de investigación antropológica ya existente, aunado al trabajo más reciente de antropólogos escogidos aquí de manera selectiva, puede contribuir al fortalecimiento del trabajo actual en el campo de los estudios del tercer sector, dado que este tiene potencial para:

- Proporcionar relatos sumamente detallados de actividades organizacionales en el nivel micro;

- Revelar la diversidad cultural de las formas organizacionales, desde los tipos informales a pequeña escala hasta las estructuras burocráticas mayores;

- Desafiar los prejuicios occidentales en el estudio de las organizaciones no lucrativas;

- Describir y analizar la cultura y el cambios organizacional empleando un amplio rango de enfoques conceptuales; 
- Vincular la investigación y la acción a nivel de comunidad o de políticas públicas a través del desarrollo de la "antropología aplicada”.

Cada uno de estos puntos puede proporcionar a los antropólogos una oportunidad de contribuir a un área de los estudios del tercer sector. Por ejemplo, las organizaciones voluntarias tienden a estar inmersas en las comunidades, en su historia y en sus culturas, y su funcionamiento depende de una compleja combinación de motivaciones tanto de los dirigentes como de los miembros, motivaciones impulsadas por valores. En todas las sociedades es posible encontrar alguna forma de actividad "voluntaria" en términos generales y, sin embargo, los valores están claramente integrados en la cultura, la cual requiere ser analizada en toda su diversidad. El estudio de las organizaciones no lucrativas está finalmente arraigado en las tradiciones de la industrialización occidental, y es muy probable que los conceptos que han emergido estén, en gran medida, culturalmente condicionados. Las culturas, tanto las organizacionales como las más amplias al interior de las sociedades, rara vez son estáticas, y cambian, evolucionan y se transforman de formas complejas. Las organizaciones no gubernamentales tienen comúnmente un carácter trasnacional. En el nivel organizacional, las formas occidentales de organización, como la burocracia, interactúan con las estructuras locales como el clan, mientras que los miembros individuales de las agencias voluntarias de desarrollo viajan a otras comunidades para proporcionar ayuda para el desarrollo. Reeves-Ellington (1995) ilustra esta problemática en el contexto de las corporaciones globales. Así como los antropólogos pueden estudiar de manera productiva los procesos y las instituciones de desarrollo (Gardner y Lewis, 1996), también puede haber beneficios potenciales para los académicos y los profesionales de una gran variedad de perspectivas en torno al tercer sector.

Mientras que en este documento se ha argumentado que la antropología puede aportar nuevas ideas y conocimientos a los estudios del tercer sector, lo contrario también puede ser verdad. La antropología ha pasado por un largo periodo de búsqueda interior desde el cual está surgiendo hacia un futuro incierto. Ahmed y Shore (1995: 15-16) escriben que: 
La antropología social como la conocemos está en peligro de verse marginada y resultar redundante a menos que adapte sus más queridas teorías, métodos y prácticas al mundo cambiante que amenaza con comprender. Esto significa, sobre todo, una revaloración del objeto de estudio y el desarrollo de nuevos dominios y métodos de búsqueda en proporción a los nuevos sujetos y fuerzas sociales que emergen en el mundo contemporáneo. Significa también comprometerse con problemáticas de mayor interés general.

Puede haber, por lo tanto, beneficios para al antropología y los antropólogos en términos de mayor relevancia en las políticas públicas partiendo de un mayor interés en el desarrollo del tercer sector, el cual ha sido aclamado en algunos medios como uno de los cambios sociales más significativos de los años recientes. La subdisciplina de la antropología aplicada (Cernea, 1995), con su conflictiva relación con la antropología general, podría verse particularmente beneficiada de un compromiso más activo con estas problemáticas. El potencial que la antropología ofrece a los estudios del tercer sector podría, en última instancia, beneficiar a ambas comunidades de investigadores.

\section{Bibliografía}

Ahmed, Akbar S. and Cris Shore, eds. (1995), The Future of Anthropology: Its Future in the Contemporary World, London, The Athlone Press.

Anderson, Robert T. (1964), "Voluntary Associations in Hyderabad", Anthropological Quarterly 37: 175-190.

Anderson, Robert T. and Gallatin Anderson (1959), "Voluntary associations and urbanization: a diachronic analysis", American Journal of Sociology 65: 265-273.

Anheier, Helmut K. (1987), "Indigenous Voluntary Associations, Non-profits and Development in Africa", in W.W. Powell, ed., The Nonprofit Sector: A Research Handbook, Yale, Yale University Press, pp. 416-433.

Banton, Michael (1968), "Voluntary Associations: Anthropological Aspects", in International Encyclopedia of the Social Sciences 16: 357-362. 
Bate, S.P. (1997), "Whatever Happened to Organizational Ethnography?”, Human Relations 50: 1147-1175.

Billis, David (1993), Organizing Public and Voluntary Agencies, London, Routledge.

Billis, David and Margaret Harris, eds. (1996), Voluntary Agencies, London, Macmillan.

Cernea, Michael (1995), "Social Organization and Development Anthropology”, Human Organization 54(3): 340-352.

Chambers, Erve (1985), Applied Anthropology, New Jersey, Prentice Hall.

Chhetri, Ram B. (1995), "Rotating Credit Associations in Nepal: Dhikuri as Capital, Credit, Saving and Investment", $\mathrm{Hu}$ man Organization, 24: 449-454.

Edwards, Michael and David Hulme, eds. (1995), Beyond the Magic Bullet: NGO Performance and Accountability, London, Earthscan.

Edwards, Michael and David Hulme, eds. (1992), Making A Difference: NGOs and Development in a Changing World, London, Earthscan.

Escobar, Arturo (1995), Encountering Development: The Making and Unmaking of the Third World, Princeton, Princeton University Press.

Etzioni, Amitai (1961), A Comparative Analysis of Complex Organizations, New York, Free Press.

Farrington, John and Anthony J. Bebbington with Kate Wellard and David J. Lewis (1993), Reluctant Partners?: NGOs, the State and Sustainable Agricultural Development, London, Routledge.

Ferguson, James (1990), The Anti-Politics Machine, Cambridge, Cambridge University Press. 
Fisher, Julie (1994), "Is the Iron law of Oligarchy Rusting Away in the Third World?”, World Development 22: 129-143.

Gardner, Katy and David Lewis (1996), Anthropology, Development and the Postmodern Challenge, London, Pluto Press.

Geertz, Clifford (1962), “The Rotating Credit Association: A 'Middle Rung' in Development", Economic Development and Cultural Change 10: 241-261.

Geertz, Clifford (1973), The Interpretation of Cultures, New York, Basic Books.

Gledhill, John (1994), Power and Its Disguises, London, Pluto.

Hamer, John H. (1967), "Voluntary Associations as Structures of Change among the Sidamo of Southwestern Ethiopia”, Anthropological Quarterly 40: 73-91.

Hann, Chris and Elizabeth Dunn (1996), Civil Society: Challenging Western Models, London, Routledge.

Haviland, William A. (1974), Anthropology, New York, Holt, Rinehart, Winston.

Herzfeld, Michael (1992), The Social Production of Indifference: Exploring the Symbolic Roots of Western Bureaucracy, New York, Berg.

Heyman, Josiah McC. (1995), "Putting Power in the Anthropology of Bureaucracy”, Current Anthropology 36: 261-287.

Horton Smith, David (1997), "Grassroots Associations are Important: Some Theory and a Review of the Impact Literature", Nonprofit and Voluntary Sector Quarterly 26: 269306.

Hulme, David and Michael Edwards, eds. (1997), Too Close for Comfort? NGOs States and Donors, London, Macmillan. 
Kerri, James N. (1976), "Studying Voluntary Associations as Adaptive Mechanisms: A Review of Anthropological Perspectives", Current Anthropology 17: 23-47.

Quarles van Ufford, Philip (1993), “Development Policy as a Failed Ritual: Evaporating and Freezing Interventions, or How to Cope with the Problem of Loosely Interconnected Practices", Paper to European Inter-University Development Opportunities Study Group (EIDOS) Conference, University of Kent, England.

Reeves-Ellington, Richard (1995), “Organizing for Global Effectiveness: Ethnicity and Organizations”, Human Organization, 54: 249-262.

Rochester, Colin (1998), "Measuring the Value of Community Sector Organizations", Centre for Voluntary Organization, London School of Economics.

Salamon, Lester C. and Helmut K. Anheier (1997), The Third Sector in Comparative Perspective, Manchester, Manchester University Press.

Salamon, Lester C. (1994), Partners In Public Service: Government-Nonprofit Relations in the Modem Welfare State, Baltimore, Johns Hopkins.

Salisbury, R. (1977), "A Prism of Perceptions: the James Bay Hydro-electricity Project”, In S. Wallman ed., Perceptions of Development, Cambridge, Cambridge University Press.

Sills, D. (1968), "Voluntary Associations: Sociological Aspects", in International Encyclopedia of the Social Sciences 16: 362-379.

Stirrat, R.L. and Heiko Henkel (1997), “The Development Gift: The Problem of Reciprocity in the NGO World", The Annals of the American Academy of Political and Social Science 554: 66-80.

Van Willingen, John (1993), Applied Anthropology: An Introduction, Revised edition, London, Bergin and Garvey. 
Vandergeest, Peter (1991), "Gifts and Rights: Cautionary Notes on Community Self-help in Thailand", Development and Change 22: 421-443.

Weisbrod, Burton (1977), The Voluntary Non-Profit Sector, Lexington, Mass, D.C. Heath and Co.

Wright, Susan (1995), "Anthropology: Still the Uncomfortable Discipline?", in A. S. Ahmed and C. Shore, eds., The Future of Anthropology: Its Future in the Contemporary World, London, The Athlone Press, pp 65-93.

Wright, Susan, ed. (1994), Anthropology of Organizations, London, Routledge.

Enviado: 19 de julio de 2000. Aceptado: 21 de febrero de 2001. 
